\title{
Metabolite Profiling, Pharmacokinetics, and In Vitro Glucuronidation of Icaritin in Rats by Ultra-Performance Liquid Chromatography Coupled with Mass Spectrometry
}

\author{
Beibei Zhang, Xiaoli Chen, Rui Zhang, Fangfang Zheng, Shuzhang Du, and Xiaojian Zhang \\ Department of Pharmacy, The First Affiliated Hospital of Zhengzhou University, Zhengzhou, Henan 450052, China \\ Correspondence should be addressed to Shuzhang Du; dushuzhang911@163.com and Xiaojian Zhang; zhangxiaojian_yxb@163.com
}

Received 5 April 2017; Accepted 23 May 2017; Published 10 July 2017

Academic Editor: Filomena Conforti

Copyright (c) 2017 Beibei Zhang et al. This is an open access article distributed under the Creative Commons Attribution License, which permits unrestricted use, distribution, and reproduction in any medium, provided the original work is properly cited.

\begin{abstract}
Icaritin is a naturally bioactive flavonoid with several significant effects. This study aimed to clarify the metabolite profiling, pharmacokinetics, and glucuronidation of icaritin in rats. An ultra-performance liquid chromatography coupled with mass spectrometry (UPLC-MS) assay was developed and validated for qualitative and quantitative analysis of icaritin. Glucuronidation rates were determined by incubating icaritin with uridine diphosphate glucuronic acid- (UDPGA-) supplemented microsomes. Kinetic parameters were derived by appropriate model fitting. A total of 30 metabolites were identified or tentatively characterized in rat biosamples based on retention times and characteristic fragmentations, following proposed metabolic pathway which was summarized. Additionally, the pharmacokinetics parameters were investigated after oral administration of icaritin. Moreover, icaritin glucuronidation in rat liver microsomes was efficient with $\mathrm{CL}_{\text {int }}$ (the intrinsic clearance) values of $1.12 \mathrm{and} 1.56 \mathrm{~mL} / \mathrm{min} / \mathrm{mg}$ for icaritin-3-O-glucuronide and icaritin-7-O-glucuronide, respectively. Similarly, the $\mathrm{CL}_{\text {int }}$ values of icaritin-3-O-glucuronide and icaritin-7-O-glucuronide in rat intestine microsomes (RIM) were 1.45 and $0.86 \mathrm{~mL} / \mathrm{min} / \mathrm{mg}$, respectively. Taken altogether, dehydrogenation at isopentenyl group and glycosylation and glucuronidation at the aglycone were main biotransformation process in vivo. The general tendency was that icaritin was transformed to glucuronide conjugates to be excreted from rat organism. In conclusion, these results would improve our understanding of metabolic fate of icaritin in vivo.
\end{abstract}

\section{Introduction}

Herba Epimedii, the dried aerial parts of Epimedium L. (Berberidaceae), are a widely used Chinese medicine for impotence, bone loss, and cardiovascular diseases [1-3]. Prenylflavonoids are reported to be a group of major active constituents present in Epimedium for the antioxidative stress, anti-inflammatory, antitumor, and antiosteoporosis activities [4-8]. Icaritin is the common aglycone with many biological effects, especially antiosteoporosis activities $[5,7]$. Besides, icaritin could induce cell death in activated hepatic stellate cells through mitochondrial activated apoptosis and ameliorate the development of liver fibrosis in rats [9]. Meanwhile, icaritin is able to target androgen receptor and androgen receptor $\mathrm{COOH}$-terminal truncated splice variants, to inhibit androgen receptor signaling and tumor growth with no apparent toxicity [10]. Additionally, icaritin has neuroprotective effects against $\mathrm{MPP}^{+}$-induced toxicity in MES23.5 cells. IGF-I receptor mediated activation of PI3K/Akt and MEK/ERK1/2 pathways are involved in the neuroprotective effects of icaritin against $\mathrm{MPP}^{+}$-induced neuronal damage [11]. Recently, icaritin had been shown as a potential agent for the treatment of systemic lupus erythematosus [12].

These biological activities above had stimulated increasing interests in the in vivo metabolism of icaritin or its related prenylflavonoids. Poor bioavailability of prenylated flavonoids results from their poor intrinsic permeation and transporter-mediated efflux by the human intestinal Caco-2 model and the perfused rat intestinal model [13]. Meanwhile, it is shown that Epimedium flavonoids could be hydrolyzed into secondary glycosides or aglycone by intestinal flora or enzymes, thereby enhancing their absorption and antiosteoporosis activity [14]. So far, numerous researches of total prenylflavonoids or individual flavonoid had been conducted in the fields of in vivo metabolites profiling, biliary excretion, and pharmacokinetics [15-19]. Generally, the in vivo 
metabolism of Herba Epimedii extracts or its prenylflavonoids could easily be metabolized in gastrointestinal tract following deglycosylation reaction. Additionally, icaritin was easily metabolized into glucuronidation conjugates to be preferentially eliminated and excreted from rat organism [16, 18, 20]. Though the data on metabolic researches of icaritin abounds, its metabolic profile is not so clear. It is essential to systematically characterize the in vivo metabolites in order to better understand its mechanism of action. Hence, the present study aimed to conduct the metabolites screening, quantitative determination, and in vitro glucuronidation of icaritin.

Recently, liquid chromatography coupled with mass spectrometry (LC-MS) had been widely introduced to rapidly screen trace components in biological samples [21, 22]. In this study, icaritin-related metabolites were analyzed based on characteristic fragmentation by UPLC-MS after oral administration. Meanwhile, possible disposing pathway of icaritin was proposed. Furthermore, a UPLC-MS method was developed and applied to perform the pharmacokinetics of icaritin. Moreover, glucuronidation rates were determined by incubating icaritin with uridine diphosphate glucuronic acid- (UDPGA-) supplemented rat liver microsomes (RLM) and rat intestine microsomes (RIM). Kinetic parameters were derived by appropriate model fitting. Icaritin was subjected to significant hepatic and gastrointestinal glucuronidation.

\section{Materials and Methods}

2.1. Materials. Icaritin, epimedin C, icariside I, icariside II, and desmethylicaritin (purity > 98\%) were purchased from Nanjing Jingzhu Medical Technology Co., Ltd. Uridine diphosphate glucuronic acid (UDPGA), magnesium chloride $\left(\mathrm{MgCl}_{2}\right)$, alamethicin, $\mathrm{D}$-saccharic-1, and 4-lactone were provided from Sigma-Aldrich (St. Louis, MO). Rat liver microsomes (RLM) and rat intestine microsomes (RIM) were prepared in our laboratory based on the protocol [21]. HPLC grade methanol and acetonitrile were purchased from Dikma Scientific and Technology Co., Ltd. All other chemicals were of analytical grade.

2.2. Animals. Male Sprague-Dawley rats $(180 \sim 220) \mathrm{g}$ were provided by Guangdong Medical Laboratory Animal Center. The rats were kept in an animal room at constant temperature $(24 \pm 2)^{\circ} \mathrm{C}$ and humidity $(60 \pm 5) \%$ with $12 \mathrm{~h}$ of light/dark per day and free access to water and food. The animal protocols were approved and conducted in accordance with the guidelines of Laboratory Animal Ethics Committee of Zhengzhou University.

2.3. Samples Collection and Preparation for Qualitative Anal$y$ sis. After the rats were fasted for $12 \mathrm{~h}$ with free access to water before experiments, icaritin dissolved in $0.3 \%$ sodium carboxymethyl cellulose solution was orally administrated to rats at a dose of $100 \mathrm{mg} / \mathrm{kg}$. Blood samples were collected from external jugular vein into heparinized tubes and were separated by centrifuging at $13800 \mathrm{~g}$ for $10 \mathrm{~min}$ at $4^{\circ} \mathrm{C}$, respectively. Bile samples were collected and recorded during
$0-24 \mathrm{~h}$ period after an abdominal incision anesthetized with $10 \%$ aqueous chloral hydrate. The urine and feces samples were collected separately during $0-24 \mathrm{~h}$ period after oral administration. Small intestinal samples were obtained after oral administration for $24 \mathrm{~h}$. All blank samples were obtained in the same way.

Before experiments, all biosamples were stored at $-20^{\circ} \mathrm{C}$. In this work, solid phase extraction method was applied to pretreat all samples. Before use, C18 columns $\left(3 \mathrm{~cm}^{3}, 60 \mathrm{mg}\right)$ were first preconditioned and equilibrated with $3 \mathrm{~mL}$ of methanol and $3 \mathrm{~mL}$ of water, respectively. Urine samples were evaporated and concentrated at $40^{\circ} \mathrm{C}$ under reduced pressure. Feces samples and small intestinal samples were dried in air and stirred into powder. And then they were treated with an ultrasonic bath for $30 \mathrm{~min}$. The filtrate was combined and evaporated to dryness at $40^{\circ} \mathrm{C}$ in vacuum. The residue was reconstituted with water. Plasma, urine, bile, feces, and small intestinal samples were loaded on pretreated columns. The residue was reconstituted in $200 \mu \mathrm{L}$ of $60 \%$ methanol and filtered through a $0.22 \mu \mathrm{m}$ membrane until injection.

2.4. Samples Preparation for Quantitative Analysis. Plasma sample $(200 \mu \mathrm{L})$ was treated with methanol $(1.2 \mathrm{~mL})$, after which the mixture was vortex-mixed for $30 \mathrm{~s}$ and centrifuged at $13800 \mathrm{~g}$ for $10 \mathrm{~min}$ at $4^{\circ} \mathrm{C}$. The supernatant was then transferred and evaporated to dryness using $\mathrm{N}_{2}$ at room temperature. The residue was dissolved in $200 \mu \mathrm{L}$ of $60 \%$ methanol and was then injected into the UPLC-MS system.

2.5. Preparation of Standard Solutions. Blank rat plasma was spiked with standard working solutions to achieve final concentration of icaritin of 2.0, 4.0, 16.0, 64.0, 128.0, 256.0, and $512.0 \mathrm{ng} / \mathrm{mL}$. All reference standard solutions were stored at $4^{\circ} \mathrm{C}$ until use.

2.6. Glucuronidation Assay. Icaritin was incubated with RLM and RIM to determine the rates of glucuronidation as published references previously [23]. Briefly, the incubation mixture mainly contained $50 \mathrm{mM}$ Tris-hydrochloric acid buffer $(\mathrm{pH}=7.4), 0.88 \mathrm{mM} \mathrm{MgCl}_{2}, 22 \mu \mathrm{g} / \mathrm{mL}$ alamethicin, $4.4 \mathrm{mM}$ saccharolactone, and $3.5 \mathrm{mM}$ UDPGA. The reaction was terminated by adding ice-cold acetonitrile. The samples were vortexed and centrifuged at $13800 \mathrm{~g}$ for $10 \mathrm{~min}$. The supernatant was subjected to UPLC-MS analysis. All experiments were performed in triplicate.

2.7. UPLC-MS Conditions. UPLC was performed using an ACQUITY $^{\mathrm{TM}}$ UPLC system (Waters, Milford, MA, USA). Separation was achieved on a Waters BEH C18 column $(1.7 \mu \mathrm{m}, 2.1 \times 50 \mathrm{~mm})$ maintained at $35^{\circ} \mathrm{C}$. The mobile phase consisted of water (A) and acetonitrile (B) (both containing $0.1 \%$ formic acid), and the flow rate was $0.5 \mathrm{~mL} / \mathrm{min}$. The gradient elution program was as follows: $0 \mathrm{~min}, 15 \% \mathrm{~B} ; 3 \mathrm{~min}$ $35 \% \mathrm{~B} ; 7 \mathrm{~min} 60 \% \mathrm{~B} ; 8 \mathrm{~min} 100 \% \mathrm{~B}$. An aliquot of $4 \mu \mathrm{L}$ sample was then injected into the UPLC-MS system.

The UPLC system was coupled to a Waters Xevo TQD (Waters, Milford, MA, USA) with electrospray ionization. 
The operating parameters were as follows: capillary voltage, $2.5 \mathrm{kV}$ (ESI+); sample cone voltage, $30.0 \mathrm{~V}$; extraction cone voltage, $4.0 \mathrm{~V}$; source temperature, $100^{\circ} \mathrm{C}$; desolvation temperature, $300^{\circ} \mathrm{C}$; and desolvation gas flow, $800 \mathrm{~L} / \mathrm{h}$. The method employed lock spray with leucine enkephalin $(\mathrm{m} / \mathrm{z}$ 556.2771 in positive ion mode and $\mathrm{m} / z 554.2615$ in negative ion mode) to ensure mass accuracy.

2.8. Pharmacokinetic Application. After fasting with free access to water for $12 \mathrm{~h}$, icaritin was given to rats as a dosage of $100 \mathrm{mg} / \mathrm{kg}$. Plasma samples were then obtained at $0.083,0.25$, $0.5,1,2,3,4,6,8,12,24,36$, and $48 \mathrm{~h}$ after administration. For pharmacokinetic application, DAS 2.0 was used to calculate the pivotal pharmacokinetic parameters.

2.9. Enzymes Kinetic Evaluation. Serial concentrations of icaritin $(0.4 \sim 20 \mu \mathrm{M})$ were incubated with RLM and RIM to determine icaritin glucuronidation rates. The kinetic models Michaelis-Menten equation and substrate inhibition equation were fitted to the data of metabolic rates versus substrate concentrations and displayed in (1) and (2), respectively. Appropriate models were selected by visual inspection of the Eadie-Hofstee plot [24]. Model fitting and parameter estimation were performed by Graphpad Prism V5 software (San Diego, CA).

The parameters were as follows. $V$ is the formation rate of product. $V_{\max }$ is the maximal velocity. $K_{\mathrm{m}}$ is the Michaelis constant and $[S]$ is the substrate concentration. $K_{\mathrm{si}}$ is the substrate inhibition constant. The intrinsic clearance $\left(\mathrm{CL}_{\text {int }}\right)$ was derived by $V_{\max } / K_{\mathrm{m}}$ for Michaelis-Menten and substrate inhibition models.

$$
\begin{aligned}
& V=\frac{V_{\max } \times[S]}{K_{\mathrm{m}}+[S]}, \\
& V=\frac{V_{\max } \times[S]}{K_{\mathrm{m}}+[S]\left(1+[S] / K_{\mathrm{si}}\right)} .
\end{aligned}
$$

\section{Results}

3.1. Fragment Pattern of Icaritin. As had already been reported in the previous study [16], besides the typical adduct ion $[\mathrm{M}+\mathrm{Na}]^{+}$at $m / z 391.1151\left(\mathrm{C}_{21} \mathrm{H}_{20} \mathrm{O}_{6} \mathrm{Na}\right)$ and $[\mathrm{M}+\mathrm{H}]^{+}$at $m / z 369.1336\left(\mathrm{C}_{21} \mathrm{H}_{21} \mathrm{O}_{6},-0.5 \mathrm{ppm}\right)$, the ion at $m / z 313.0714\left(\mathrm{C}_{17} \mathrm{H}_{13} \mathrm{O}_{6}\right)$ in positive ion mode was considered as the characteristic fragment ion (see Figure Sla in the Supplementary Material available online at https://doi.org/10.1155/2017/1073607).

3.2. Screening of Metabolites. On the basis of MS/MS fragmentation pattern, the metabolites were deduced, clarifying the general metabolism in vivo. The extracted ion chromatograms (EICs) of prototype (M0) and metabolites (M1 M30) were shown in Figure 1, while the individual EICs of M1 M30 were exhibited in Figure S2. The UV, MS, and MS/MS data of M0 M30 were all exhibited in Table 1.

\subsection{Structure Elucidation of Metabolites}

M0 (Parent Drug). M0 (7.20 min, $\left.\mathrm{C}_{21} \mathrm{H}_{20} \mathrm{O}_{6},-0.5 \mathrm{ppm}\right)$ in biological samples was unambiguously identified by comparing with references.

M15 and M23 (Hydration of Isopentene Group). Based on the $[\mathrm{M}+\mathrm{H}]^{+}$ion at $m / z 387.1445\left(\mathrm{C}_{21} \mathrm{H}_{23} \mathrm{O}_{7}, 0.3 \mathrm{ppm}\right)$ and $[\mathrm{M}-\mathrm{H}]^{-}$ion at $m / z 385.1286\left(\mathrm{C}_{21} \mathrm{H}_{21} \mathrm{O}_{7}\right)$, the molecular formula of M15 (4.34 min) and M23 (4.97 min) was determined as $\mathrm{C}_{21} \mathrm{H}_{22} \mathrm{O}_{7}$, with one $\mathrm{H}_{2} \mathrm{O}$ more than M0. The MS/MS spectrum of $[\mathrm{M}+\mathrm{H}]^{+}$ion $\left(\mathrm{C}_{21} \mathrm{H}_{23} \mathrm{O}_{7}\right)$ showed predominant $\left[\mathrm{M}+\mathrm{H}-\mathrm{H}_{2} \mathrm{O}\right]^{+}$ion at $\mathrm{m} / z \quad 369.1343$ and 313.0715 (Figure $\mathrm{S} 1 \mathrm{~b})$, which indicated that M15 and M23 were the hydration products at isopentene group of icaritin and agreed with previous study of icariin [18].

M25 (Demethylation of Flavonoid Aglycone). According to the $[\mathrm{M}+\mathrm{H}]^{+}$ion at $m / z 355.1180\left(\mathrm{C}_{20} \mathrm{H}_{19} \mathrm{O}_{6},-0.6 \mathrm{ppm}\right)$ and $[\mathrm{M}-\mathrm{H}]^{-}$ion at $m / z 353.1036\left(\mathrm{C}_{20} \mathrm{H}_{17} \mathrm{O}_{6}\right)$, the formula of $\mathrm{M} 25$ (5.08 min) was supposed as $\mathrm{C}_{20} \mathrm{H}_{18} \mathrm{O}_{6}$, with a methyl group less than M0. The MS/MS experiments (Figure S1c) showed a significant loss of neutral loss of $\mathrm{C}_{4} \mathrm{H}_{8}(56.0626 \mathrm{Da})$ from the ion at $\mathrm{m} / \mathrm{z} 355.1180$ to 299.0582 in positive ion mode or from the ion at $m / z 353.1036$ to 297.0373 in negative ion mode. Meanwhile, the demethylation position was purposed at $4^{\prime}$ position of B ring of flavonoid aglycone. Moreover, M25 was identified as desmethylicaritin by comparison of reference standard.

M30 (Dehydrogenation of Isopentene Group). The formula of M30 $(6.36 \mathrm{~min})$ was $\mathrm{C}_{21} \mathrm{H}_{18} \mathrm{O}_{6}$, with two hydrogens fewer than M0, based on the $[\mathrm{M}+\mathrm{H}]^{+}$ion at $\mathrm{m} / z 367.1180$ $\left(\mathrm{C}_{21} \mathrm{H}_{19} \mathrm{O}_{6},-0.5 \mathrm{ppm}\right)$ and $[\mathrm{M}-\mathrm{H}]^{-}$ion at $\mathrm{m} / z 365.1047$ $\left(\mathrm{C}_{21} \mathrm{H}_{17} \mathrm{O}_{6}\right)$. In MS/MS spectrum (Figure S1d), the ions at $\mathrm{m} / \mathrm{z} 352.0948$ and 313.0721 were attributed to obvious loss of $\mathrm{CH}_{3}(15.0235 \mathrm{Da})$ and $\mathrm{C}_{4} \mathrm{H}_{6}(54.0470 \mathrm{Da})$ group, respectively, which indicated that the dehydrogenation position was at isopentene group [18].

M27 M29 (Hydroxylation of Isopentene Group). From the $[\mathrm{M}+\mathrm{H}]^{+}$ion at $m / z 385.1288\left(\mathrm{C}_{21} \mathrm{H}_{21} \mathrm{O}_{7}, 0.3 \mathrm{ppm}\right)$ and [M-H] $]^{-}$ion at $m / z 383.1175\left(\mathrm{C}_{21} \mathrm{H}_{19} \mathrm{O}_{7}\right)$, the formulae of M27 (5.37 min, $\left.\lambda_{\max } 268 \mathrm{~nm}\right)$, M28 $(5.54 \mathrm{~min})$, and M29 (5.66 min) were speculated as $\mathrm{C}_{21} \mathrm{H}_{20} \mathrm{O}_{7}$, which was one oxygen more than M0. In (+) ESI-MS/MS spectrum (Figure S1e), the ion at $m / z 385.1288$ could lose $\mathrm{H}_{2} \mathrm{O}$ and $\mathrm{C}_{4} \mathrm{H}_{6}$ group to produce the daughter ions at $367.1186\left(\left[\mathrm{M}+\mathrm{H}-\mathrm{H}_{2} \mathrm{O}\right]^{+}\right)$and $313.0715\left(\left[\mathrm{M}+\mathrm{H}-\mathrm{C}_{4} \mathrm{H}_{6}\right]^{+}\right)$, respectively. This illustrated that M27 M29 were tentatively characterized as the hydroxylated products of $\mathrm{M} 0$ at the isopentene group.

M14, M16, M17, M19, M20, and M21 (Glycosylation of Flavonoid Aglycone). M21 (4.88 min) was given a $[\mathrm{M}+\mathrm{H}]^{+}$ion at $m / z 515.1927\left(\mathrm{C}_{27} \mathrm{H}_{31} \mathrm{O}_{10}, 1.9 \mathrm{ppm}\right)$ and $[\mathrm{M}-\mathrm{H}]^{-}$ion at $m / z$ $513.1766\left(\mathrm{C}_{27} \mathrm{H}_{29} \mathrm{O}_{10}\right)$ in full scan mass spectrum. The ion at $\mathrm{m} / z 515.1927$ could easily yield the characteristic fragment ions at $\mathrm{m} / \mathrm{z} 369.1340$ and 313.0726 by subsequent loss of $\mathrm{C}_{6} \mathrm{H}_{10} \mathrm{O}_{4}$ and $\mathrm{C}_{4} \mathrm{H}_{8}$ (Figure Sif). So M21 could be the glycosylation product of $\mathrm{MO}$ by adduct of rhamnose $\left(\mathrm{C}_{6} \mathrm{H}_{10} \mathrm{O}_{4}\right.$, 146.0579 Da). Similarly, M17 (4.53 min, $\mathrm{C}_{27} \mathrm{H}_{30} \mathrm{O}_{11}, 1.5 \mathrm{ppm}$ ) 


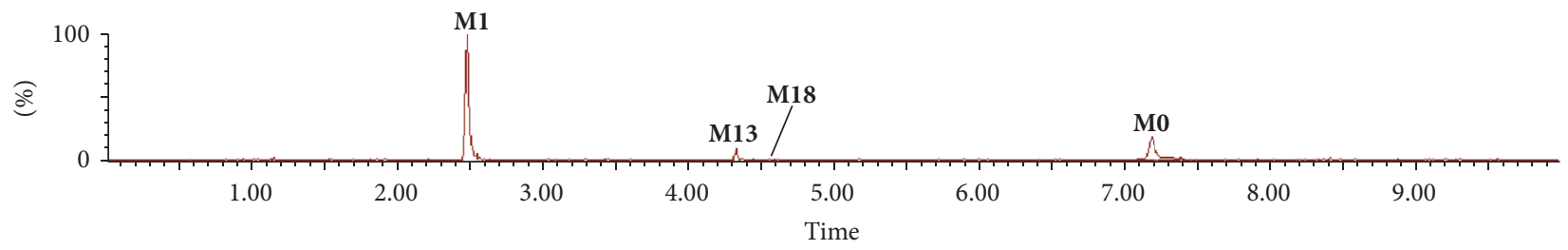

1: TOF MS ES+

$-369.134+721.198+545.1660 .0200 \mathrm{Da}$ $8.39 e 3$

(a)

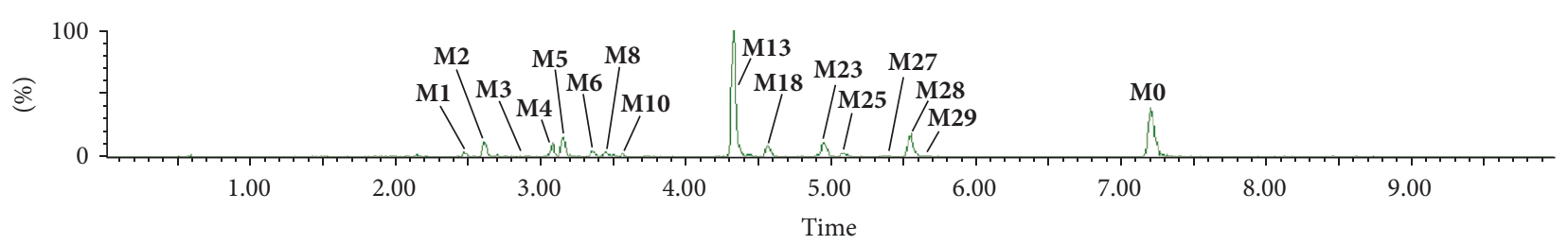

1: TOF MS ES+

— $369.134+721.198+563.177+531.151+561.161+545.166+387.144+355.118+385.129$ $3.86 e 4$

(b)

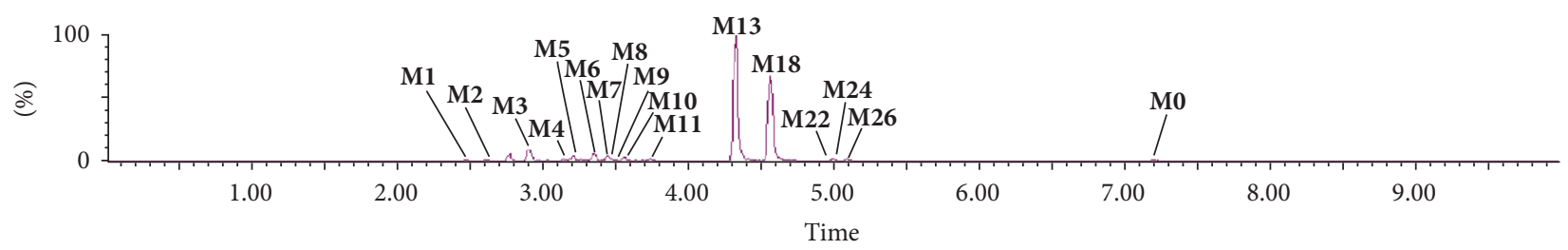

1: TOF MS ES+

$-369.134+721.198+563.177+531.151+561.162+545.1660 .0200 \mathrm{Da}$ $4.91 e 4$

(c)

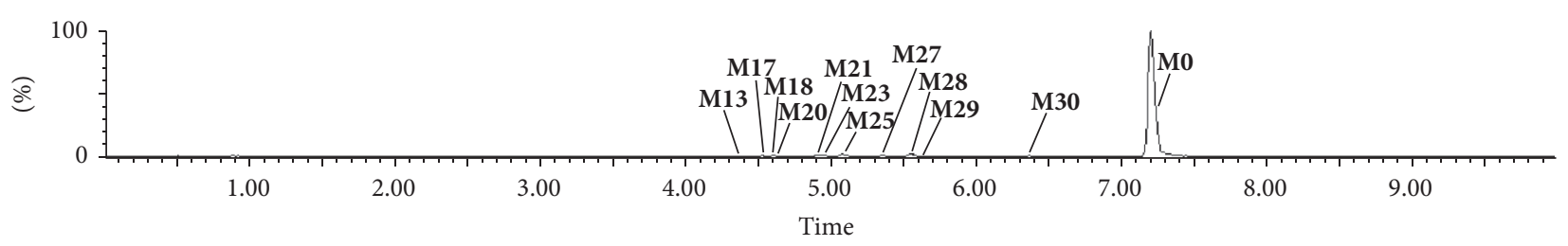

1: TOF MS ES+

$-369.134+545.166+531.187+661.25+515.193+387.144+355.118+385.129+367.118$ $1.77 e 5$

(d)

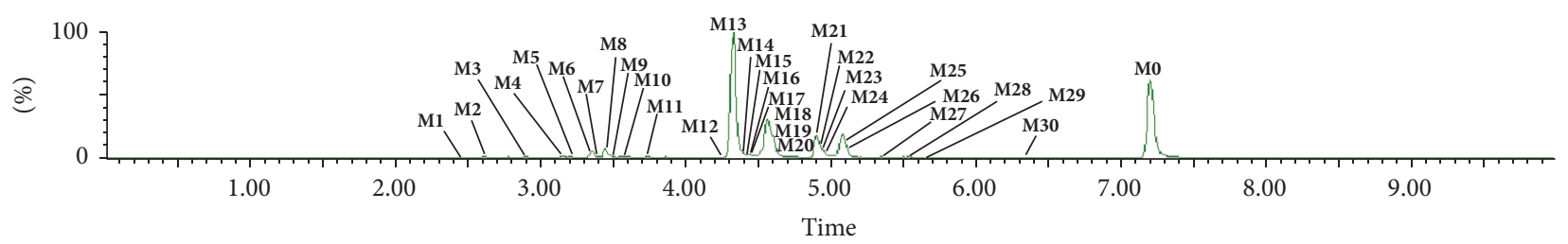

1: TOF MS ES+

Sum $0.0200 \mathrm{Da}$

$5.48 e 5$

(e)

FIGURE 1: EICs of all metabolites in rat biosamples after oral administration of icaritin. (a) Plasma; (b) urine; (c) bile; (d) feces; (e) intestine. 


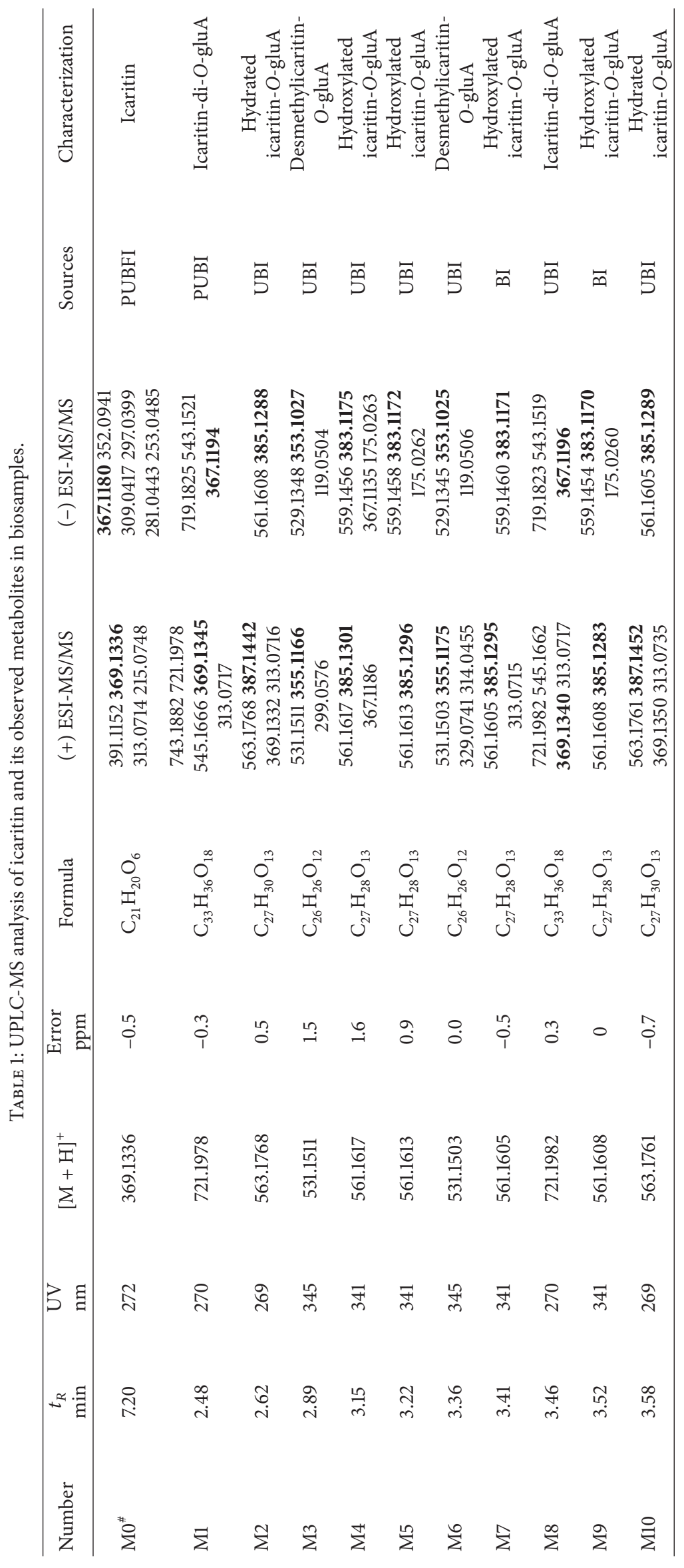




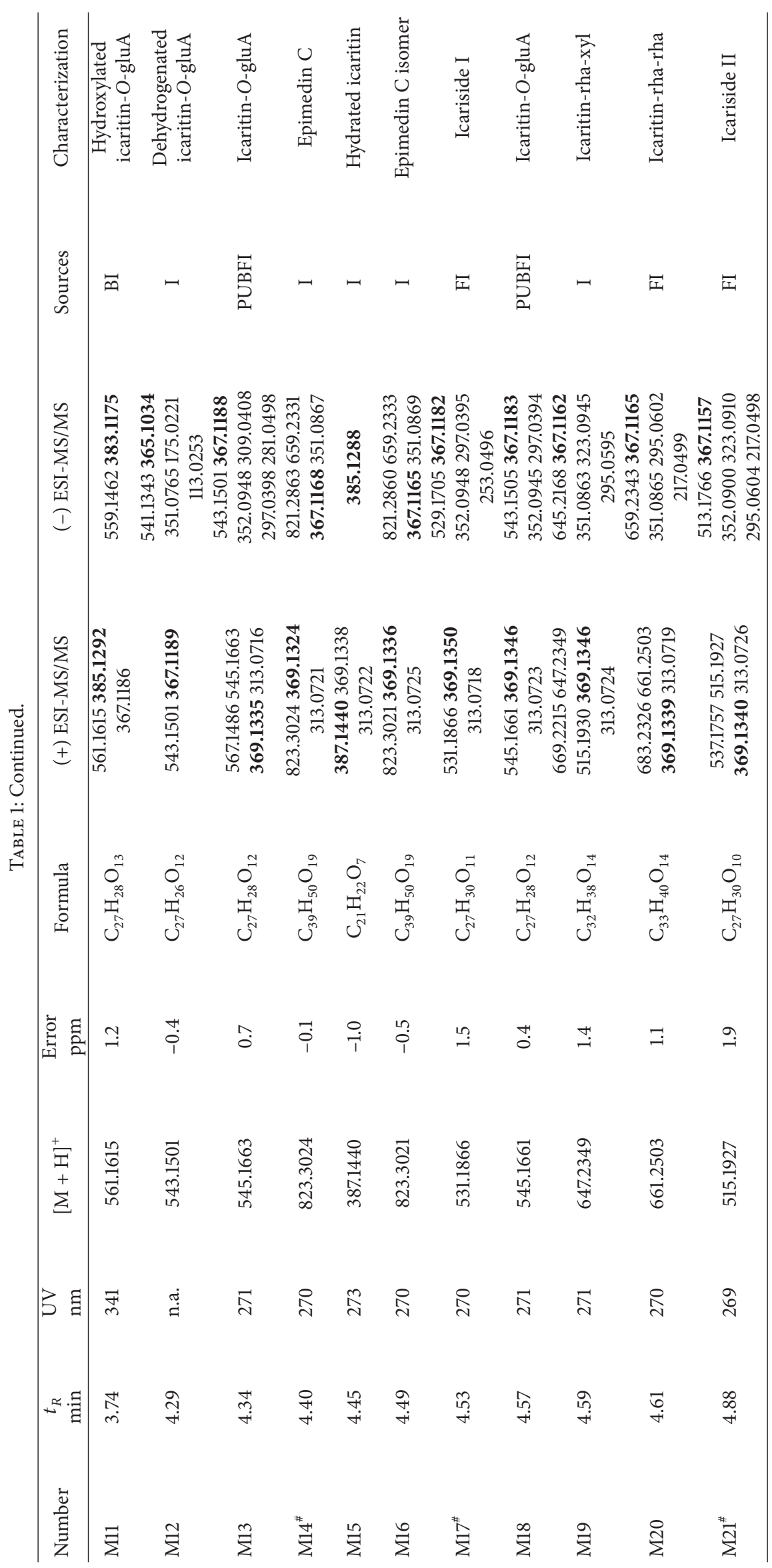




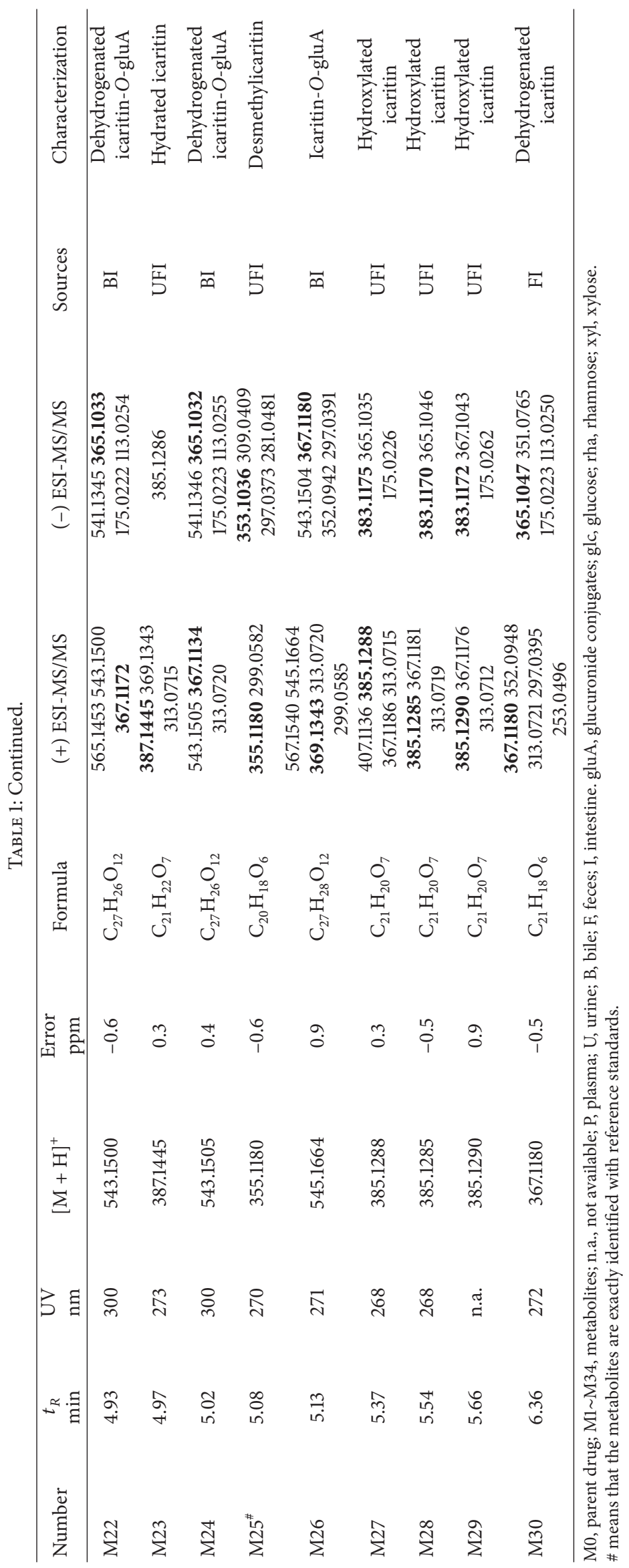


was the glucose conjugate of M0, while M19 (4.59 min, $\mathrm{C}_{32} \mathrm{H}_{39} \mathrm{O}_{14}, 1.4 \mathrm{ppm}$ ) and $\mathrm{M} 20$ (4.61 min, $\left.\mathrm{C}_{33} \mathrm{H}_{41} \mathrm{O}_{14}, 1.1 \mathrm{ppm}\right)$ were the xylose and rhamnose glycosylation derivates of M21, respectively. M14, M17, and M21 were identified as epimedin $\mathrm{C}$, icariside I, and icariside II, respectively.

M14 (4.40 min, $\lambda_{\max } 270 \mathrm{~nm}, \mathrm{C}_{39} \mathrm{H}_{51} \mathrm{O}_{19},-0.1 \mathrm{ppm}$ ) and M16 (4.49 min, $\lambda_{\max } 270 \mathrm{~nm}, \mathrm{C}_{39} \mathrm{H}_{51} \mathrm{O}_{19},-0.5 \mathrm{ppm}$ ) both with the formula of $\mathrm{C}_{39} \mathrm{H}_{50} \mathrm{O}_{19}$ (Figure $\mathrm{S} 1 \mathrm{~g}$ ) were tentatively characterized as the glucose glycosylation conjugate of M20. These glycosylation reactions were the same as the metabolism of epimedin $\mathrm{C}$ in rats reported in reference (Liu et al., 2011). By comparing with references, M14, M17, and M21 were identified as epimedin $\mathrm{C}$, icariside I, and icariside II, respectively. And the MS/MS spectra of M17, M19, and M20 were shown in Figures S1h-S1j, respectively.

M1, M8, M13, M18, and M26 (Glucuronidation of Flavonoid Aglycone). In full scan mass spectrum, M13 (4.34 min), M18 (4.57 $\mathrm{min}$ ), and M26 (5.10 min) all exhibited the $[\mathrm{M}+\mathrm{H}]^{+}$ion at $m / z 545.1663\left(\mathrm{C}_{27} \mathrm{H}_{29} \mathrm{O}_{12}, 0.7 \mathrm{ppm}\right)$ and $[\mathrm{M}-\mathrm{H}]^{-}$ion at $m / z 543.1501\left(\mathrm{C}_{27} \mathrm{H}_{27} \mathrm{O}_{12}\right)$ with a formula of $\mathrm{C}_{27} \mathrm{H}_{28} \mathrm{O}_{12}$ of $176.0325 \mathrm{Da}$ larger than M0. The MS/MS spectrum (Figure S1k) displayed an obvious loss of $\mathrm{C}_{6} \mathrm{H}_{8} \mathrm{O}_{6}$ group from parent ion at $m / z 545.1663$ to the daughter ion at $m / z$ 369.1338 , which suggested an existing glucuronic acid of these three metabolites. Just like reported studies [16], monoglucuronide conjugate and diglucuronide conjugate were widely distributed in biological samples after oral administration of Epimedium-related total flavonoids or individual flavonoid. Therefore, M13, M18, and M26 were tentatively identified as monoglucuronidation conjugate of $\mathrm{M} 0$, while $\mathrm{M} 1$ (2.48 $\left.\mathrm{min}, \mathrm{C}_{33} \mathrm{H}_{36} \mathrm{O}_{18},-0.3 \mathrm{ppm}\right)$ and $\mathrm{M} 8$ (3.45 min, $\mathrm{C}_{33} \mathrm{H}_{36} \mathrm{O}_{18}, 0.3 \mathrm{ppm}$ ) (Figure S1l) were characterized as diglucuronidation derivates based on two molecules of $\mathrm{C}_{6} \mathrm{H}_{8} \mathrm{O}_{6}$ fragment larger than $\mathrm{M} 0$.

Similarly, M2 (2.62 min, $\lambda_{\max } 269 \mathrm{~nm}, \mathrm{C}_{27} \mathrm{H}_{30} \mathrm{O}_{13}$, $0.5 \mathrm{ppm}$ ) and $\mathrm{M} 10$ (3.57 $\mathrm{min}, \lambda_{\max } 269 \mathrm{~nm}, \mathrm{C}_{27} \mathrm{H}_{30} \mathrm{O}_{13}$, $-0.7 \mathrm{ppm}$ ) with the MS/MS spectrum shown in Figure S1 $\mathrm{m}$ were tentatively considered as the monoglucuronidation products of M15 and M23. M3 (2.89 min, $\lambda_{\max } 345 \mathrm{~nm}$, $\mathrm{C}_{26} \mathrm{H}_{26} \mathrm{O}_{12}, 1.5 \mathrm{ppm}$ ) and $\mathrm{M} 6$ (3.36 min, $\lambda_{\max } 345 \mathrm{~nm}$, $\mathrm{C}_{26} \mathrm{H}_{26} \mathrm{O}_{12}, 0 \mathrm{ppm}$ ) were characterized as monoglucuronide conjugate of M25. The MS/MS spectrum of M3 and M6 was exhibited in Figure S1n. Meanwhile, M4 (3.16 min, $\lambda_{\max } 341 \mathrm{~nm}, \mathrm{C}_{27} \mathrm{H}_{28} \mathrm{O}_{13}, 1.6 \mathrm{ppm}$ ), M5 (3.21 min, $\lambda_{\max }$ $341 \mathrm{~nm}, \mathrm{C}_{27} \mathrm{H}_{28} \mathrm{O}_{13}, 0.9 \mathrm{ppm}$ ), M7 (3.40 min, $\lambda_{\max } 341 \mathrm{~nm}$, $\left.\mathrm{C}_{27} \mathrm{H}_{28} \mathrm{O}_{13},-0.5 \mathrm{ppm}\right), \quad \mathrm{M} 9 \quad\left(3.50 \mathrm{~min}, \lambda_{\max } 341 \mathrm{~nm}\right.$, $\mathrm{C}_{27} \mathrm{H}_{28} \mathrm{O}_{13}, 0 \mathrm{ppm}$ ), and $\mathrm{M} 11$ (3.74 min, $\lambda_{\max } 341 \mathrm{~nm}$, $\mathrm{C}_{27} \mathrm{H}_{28} \mathrm{O}_{13}, 1.2 \mathrm{ppm}$ ) were regarded as monoglucuronidation derivates of M27 M29 and their MS/MS spectrum was displayed in Figure S1o. M12 (4.29 min, not available $\left.\lambda_{\max }, \quad \mathrm{C}_{27} \mathrm{H}_{26} \mathrm{O}_{12}, \quad-0.4 \mathrm{ppm}\right), \quad \mathrm{M} 22 \quad$ (4.94 min, $\lambda_{\max }$ $300 \mathrm{~nm}, \mathrm{C}_{27} \mathrm{H}_{26} \mathrm{O}_{12},-0.6 \mathrm{ppm}$ ), and M24 (5.02 min, $\lambda_{\max }$ $\left.300 \mathrm{~nm}, \mathrm{C}_{27} \mathrm{H}_{26} \mathrm{O}_{12}, 0.4 \mathrm{ppm}\right)$ were tentatively identified as glucuronidation conjugates of M30. And their MS/MS spectrum was shown in Figure S1p.

3.4. Method Validation. The method was validated for specificity, linearity, extraction recovery, matrix effects, precision, accuracy, and stability according to the US Food Drug Administration guidelines for bioanalytical method validation [25].

Specificity was determined by comparing the chromatograms obtained for six blank plasma samples, blank plasma samples spiked with standard solutions at LLOQ concentrations, and drug plasma samples obtained $4 \mathrm{~h}$ after oral administration. As shown in Figure S3, no interference peaks were detected at the retention times of icaritin.

The LOD and LOQ were calculated as 3-fold and 10-fold of the ratio of signal-to-noise, respectively. The LLOQ was defined as the lowest concentration in the calibration curve with accuracy of $80 \sim 120 \%$ and precision of $20 \%$. Calibration curves were acquired by plotting peak area $(y)$ versus respective plasma concentrations $(x)$ using a $1 / x^{2}$ weighting factor and linear least-squares regression analysis. A series of standard solutions were used to generate calibration curve. The correlation coefficients $\left(r^{2}\right)$ of calibration curves were greater than 0.9926 within $2.0 \sim 512.0 \mathrm{ng} / \mathrm{mL}$ and LLOQ was $2.0 \mathrm{ng} / \mathrm{mL}$. The regression equations, correlation coefficients, and LLOQ were shown in Table S1.

The experiments to evaluate matrix effect and recovery were conducted by the protocol [26]. According to the protocol, the peak areas from QC samples at three concentrations were defined as $\mathrm{Al}$; those from extracted control plasma reconstituted with standard solutions at 4.0, 64.0, and $256.0 \mathrm{ng} / \mathrm{mL}$ were A2. The responses of icaritin found by direct injection of the corresponding pure reference standards at three QC levels were A3. The matrix effect and recovery were calculated as follows: matrix effect $(\%)=$ $\mathrm{A} 2 / \mathrm{A} 3 \times 100 \%$. Recovery $(\%)=\mathrm{A} 1 / \mathrm{A} 2 \times 100 \%$. The results (as shown in Table S2) illustrated that matrix effect was between $89.1 \%$ and $113.5 \%$, and the recovery was from $96.3 \%$ to $102.7 \%$.

The accuracy and inter/intraday precision of the method were evaluated by determining six replicates of QC samples on three consecutive days. The measured concentrations of QC samples were determined with a calibration curve obtained on the same day. Relative error and relative standard deviation were used to describe accuracy and inter/intraday precision, respectively. They both should not exceed $15 \%$. As exhibited in Table S3, the intraday and interday precision were less than $13.2 \%$ and $10.2 \%$, respectively, while the intraday and interday precision of LLOQ were no more than $17.4 \%$ and $15.6 \%$, respectively.

Stability of icaritin in rat plasma was assessed under different conditions at three concentration levels, including extracted samples for $12 \mathrm{~h}$ at room temperature, kept at $-20^{\circ} \mathrm{C}$ for $60 \mathrm{~h}$, three cycles of freezing at $-20^{\circ} \mathrm{C}$ and thawing at $25^{\circ} \mathrm{C}$, and plasma sample at room temperature for $8 \mathrm{~h}$. Each was compared by three QC replicates of the same concentration with a calibration curve in the same day. The RE was within $13.8 \%$ and RSD was less than $11.3 \%$. Stability results (Table S4) indicated that icaritin were stable under different storage conditions.

3.5. Pharmacokinetics Application. The mean concentrationtime profiles of these bioactive components were shown in Figure 2. The main pharmacokinetic parameters were illustrated in Table 2. In this study, $C_{\max }$ was $(294.5 \pm 22.7) \mathrm{ng} / \mathrm{mL}$ 


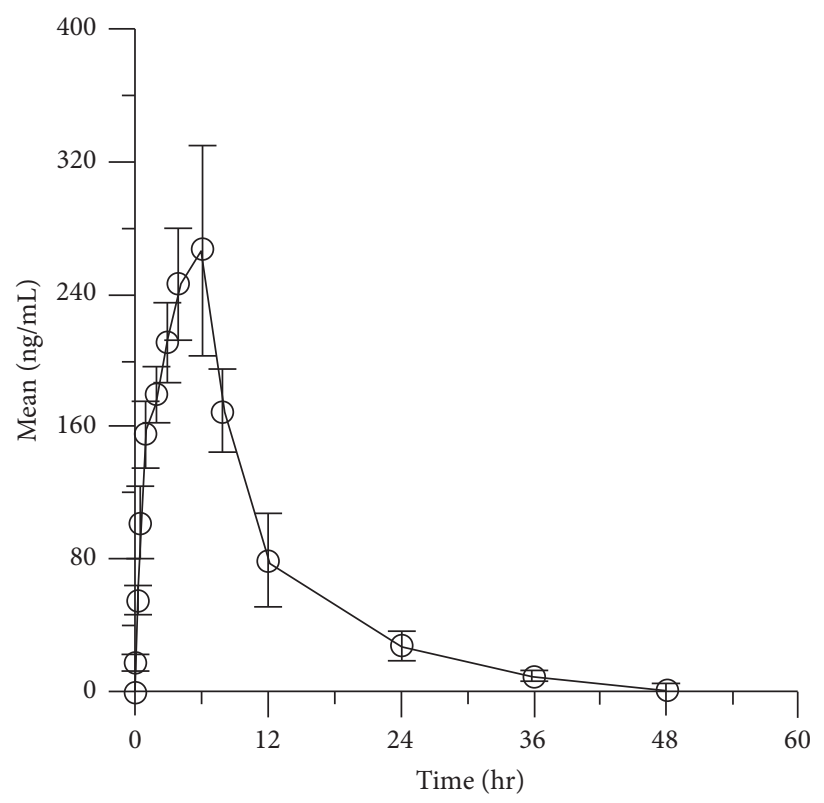

FIGURE 2: Concentration-time curve of icaritin in rat plasma after oral administration.

TABLE 2: Pharmacokinetic parameters of icaritin in rat plasma after oral administration.

\begin{tabular}{lc}
\hline Parameters & $100 \mathrm{mg} / \mathrm{kg}$ \\
\hline$T_{\max }(\mathrm{h})$ & $5.3 \pm 1.1$ \\
$C_{\text {max }}(\mathrm{ng} / \mathrm{mL})$ & $294.5 \pm 22.7$ \\
$t_{1 / 2}(\mathrm{~h})$ & $8.3 \pm 1.0$ \\
$\mathrm{AUC}_{0-t}(\mathrm{ng} \cdot \mathrm{h} / \mathrm{mL})$ & $3048.5 \pm 289.0$ \\
$\mathrm{AUC}_{0-\infty}(\mathrm{ng} \cdot \mathrm{h} / \mathrm{mL})$ & $3145.0 \pm 302.3$ \\
$\mathrm{MRT}_{0-t}(\mathrm{~h})$ & $9.6 \pm 1.1$ \\
$\mathrm{MRT}_{0-\infty}(\mathrm{h})$ & $10.9 \pm 1.3$ \\
\hline
\end{tabular}

when $T_{\max }$ was $(5.3 \pm 1.1) \mathrm{h}$ after oral administration. The area under the concentration-time curve $\left(\mathrm{AUC}_{0-\infty}\right)$ and mean residence time $\left(\mathrm{MRT}_{0-\infty}\right)$ were $(3145.0 \pm 302.3) \mathrm{ng} \cdot \mathrm{h} / \mathrm{mL}$ and $(10.9 \pm 1.3) \mathrm{h}$, respectively. The results illustrated that icaritin had a poor absorption after oral administration. The reason may be that icaritin stepped into small intestine to undergo mass phase I and phase II metabolism by intestinal flora, especially the glycosylation and glucuronidation conjugates.

3.6. Glucuronidation of Icaritin in RLM and RIM. Due to lack of reference standard, quantification of icaritin glucuronide was based on the standard curve of the parent compound (icaritin) according to the assumption that parent compound and its glucuronide have closely similar UV absorbance maxima [27-29]. The detection wavelength of icaritin and icaritin glucuronides was $270 \mathrm{~nm}$. The linear range of icaritin was $0.02 \sim 20 \mu \mathrm{M}$, with LOD $(S / N=3 \sim 5)$ and LOQ $(S / N=8 \sim 10)$ of 0.01 and $0.02 \mu \mathrm{M}$, respectively. And the acceptable linear correlation $(Y=12149 X)$ was confirmed by correlation coefficients $\left(r^{2}\right)$ of 0.9994 . The accuracy and precision of the intraday and interday error were both less than $3.4 \%$. There were no matrix effects observed and no other sample preparation performed except those mentioned in the manuscript.

Kinetic profiling revealed that formation of icaritin-3$\mathrm{O}$-glucuronide (M13) and icaritin-7-O-glucuronide (M18) in RLM was well modeled by the substrate inhibition equation (Figure 3(a)), whereas they followed the classical MichaelisMenten kinetics in RIM (Figure 3(b)). In contrast, the glucuronide formation of M13 (4.06 nmol/min/mg) and M18 $(2.39 \mathrm{nmol} / \mathrm{min} / \mathrm{mg})$ in RLM was similar as well as M13 $(11.88 \mathrm{nmol} / \mathrm{min} / \mathrm{mg})$ and $\mathrm{M} 18(8.23 \mathrm{nmol} / \mathrm{min} / \mathrm{mg})$ in RIM. Icaritin glucuronidation in RLM was efficient $\left(\mathrm{CL}_{\text {int }}=1.12\right.$ and $1.56 \mathrm{~mL} / \mathrm{min} / \mathrm{mg}$ for M13 and M18, resp.), following the substrate inhibition kinetics with $K_{\mathrm{m}}$ values of 3.62 and $1.53 \mu \mathrm{M}$, respectively. Similarly, the $\mathrm{CL}_{\text {int }}$ values of $\mathrm{M} 13$ and M18 in RIM were 1.446 and $0.861 \mathrm{~mL} / \mathrm{min} / \mathrm{mg}$, respectively, whereas the $K_{\mathrm{m}}$ values of M13 and M18 in RIM in MichaelisMenten model were 8.22 and $9.56 \mu \mathrm{M}$, respectively. In addition, $K_{\mathrm{i}}$ values of M13 and M18 in RLM were 11.31 and $17.07 \mu \mathrm{M}$, respectively. The detailed parameters of M13 and M18 were listed in Table 3.

\section{Discussion}

Normally, only the prototypes or metabolites in blood with a high enough exposure in target organs for a finite period of time are considered as potential effective components for therapeutic benefits [30]. In this study, M0, M1, and M13 were the main xenobiotics in plasma (Figure 1(a)), which may be the potential in vivo effective components directly. After circulation, M2, M5, M13, M23, and M28 were passed out with the urine (Figure 1(b)).

Due to poor oral bioavailability, several components were limited to be absorbed in blood. But they could influence intestinal dysfunction to exert efficacy by their prototypes, secondary metabolites, or finally the aglycone in intestinal 
TABLE 3: Kinetic parameters of icaritin glucuronidation by RLM and RIM (mean \pm SD).

\begin{tabular}{|c|c|c|c|c|c|c|}
\hline Protein source & Metabolite & $\begin{array}{c}V_{\max } \\
(\mathrm{nmol} / \mathrm{min} / \mathrm{mg}) \\
\end{array}$ & $\begin{array}{c}K_{\mathrm{m}} \\
(\mu \mathrm{M})\end{array}$ & $\begin{array}{c}K_{\mathrm{i}} \\
(\mu \mathrm{M}) \\
\end{array}$ & $\begin{array}{c}\mathrm{CL}_{\text {int }} \\
(\mathrm{mL} / \mathrm{min} / \mathrm{mg})\end{array}$ & Model \\
\hline \multirow{2}{*}{ RLM } & M13 & $4.06 \pm 0.70$ & $3.62 \pm 0.99$ & $11.31 \pm 3.51$ & $1.12 \pm 0.36$ & SI \\
\hline & M18 & $2.39 \pm 0.26$ & $1.53 \pm 0.34$ & $17.07 \pm 4.38$ & $1.56 \pm 0.38$ & SI \\
\hline \multirow{2}{*}{ RIM } & M13 & $11.88 \pm 0.60$ & $8.22 \pm 0.92$ & N.A. & $1.45 \pm 0.18$ & $\mathrm{MM}$ \\
\hline & M18 & $8.23 \pm 0.63$ & $9.56 \pm 1.51$ & N.A. & $0.86 \pm 0.15$ & MM \\
\hline
\end{tabular}

Note. SI, substrate inhibition model; MM, Michaelis-Menten model; N.A., not available.

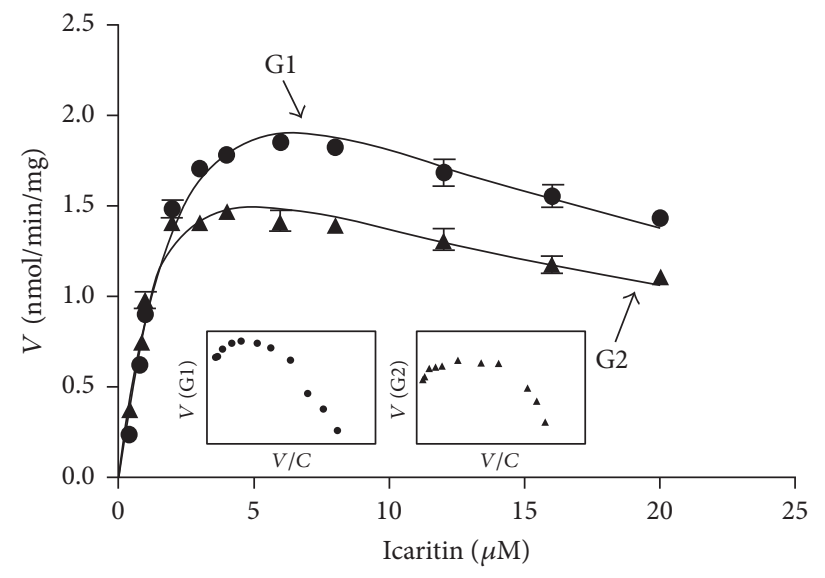

(a)

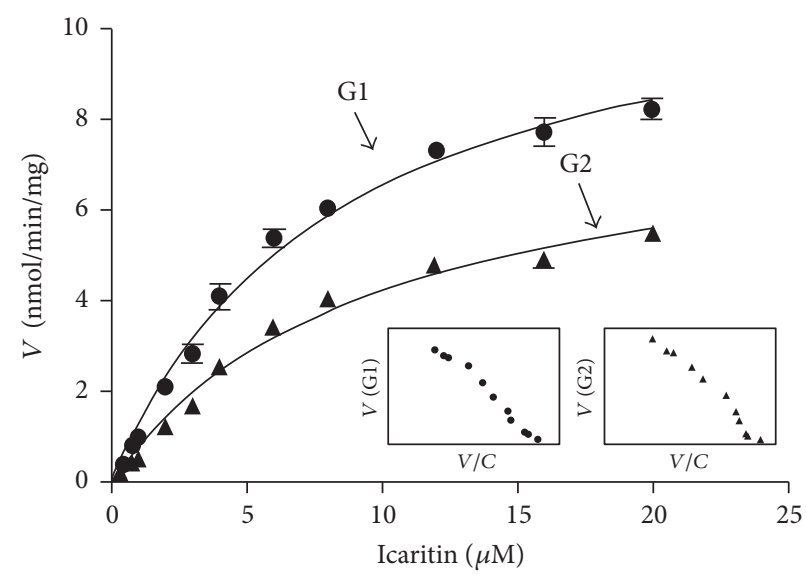

(b)

FIGURE 3: Kinetic profiles for glucuronidation of icaritin by various types of microsomes. (a) Pooled rat liver microsomes (RLM); (b) pooled rat intestine microsomes (RIM). In each panel, the insert figure showed the corresponding Eadie-Hofstee plot.

tract [31]. Massive metabolites containing M6, M8, M13, M17, M25, M28, and M30 were detected in rat feces and small intestinal samples (Figure $1(\mathrm{~d})$ ). Moreover, icaritin underwent phase II metabolism by main conjugating enzymes including UDP-glucuronosyltransferases (UGTs) to produce extensive mono- or diglucuronic acid conjugates. In rat bile, M3, M6, M13, M18, and M24 mainly were biotransformed in rat liver and excreted into bile (Figure 1(c)).

Characterization of icaritin glucuronidation assumed a great role in the understanding of its pharmacokinetics and bioavailability. Oral bioavailability is a major factor in determining the biological actions of icaritin in vivo following oral administration of the compound [32]. This study suggested that the oral bioavailability of icaritin would be influenced by first-pass glucuronidation in the liver. The glucuronidation activity was obtained by kinetic profiling and modeling. Kinetic profiling required the determination of the rates of icaritin glucuronidation at a series of icaritin concentrations. The relative activities of RLM and RIM toward icaritin glucuronidation were evaluated by the derived $\mathrm{CL}_{\text {int }}$ values (Table 3). Use of $\mathrm{CL}_{\text {int }}\left(=V_{\max } / K_{\mathrm{m}}\right)$ as an indicator of enzymes activity was advantageous, because (1) $\mathrm{CL}_{\text {int }}$ represents the catalytic efficiency of the enzyme and is independent of the substrate concentration; (2) compared with other kinetic parameters such as $K_{\mathrm{m}}$ and $V_{\text {max }}, \mathrm{CL}_{\text {int }}$ is more relevant in an attempt to predict hepatic clearance in vivo [33]. Therefore, $\mathrm{CL}_{\text {int }}$ values were used to determine icaritin glucuronidation activity in this study.
Based on the metabolite profiles, the metabolic pathways of icaritin were proposed and shown in Figure 4(a), and the metabolic sites were shown in Figure 4(b). In summary, icaritin was hard to be absorbed into the rat blood. In small intestine, icaritin could form flavonoid glycoside by the sequential glycosylation metabolism. Meanwhile, icaritin could easily conjugate with a glucuronic acid to form phase II metabolites in liver, which indicated that the biliary clearance was one of the major routes of excretion. Phase I metabolism of icaritin mainly included demethylation, dehydrogenation, and hydration. The general tendency was that the saponins were metabolized and transformed into the high polar metabolites to be eliminated and excreted from the rat organism.

\section{Conclusion}

As a result, a total of 30 metabolites were identified or tentatively characterized based on the retention time behaviors and fragmentation patterns. Dehydrogenation at isopentenyl group and glycosylation and glucuronidation at the flavonoid aglycone were the main biotransformation process of icaritin in vivo. Meanwhile, a validated method was successfully applied to a pharmacokinetic study. Moreover, icaritin glucuronidation in RLM was efficient with $\mathrm{CL}_{\text {int }}$ values of 1.12 and $1.56 \mathrm{~mL} / \mathrm{min} / \mathrm{mg}$ for $\mathrm{M} 13$ and M18, respectively. Similarly, the $\mathrm{CL}_{\text {int }}$ values of M13 and M18 in RIM were 1.45 and $0.86 \mathrm{~mL} / \mathrm{min} / \mathrm{mg}$, respectively. Taken altogether, this 
<smiles>COc1ccc(-c2oc3c(CC(C)(C)O)c(O)cc(O)c3c(=O)c2O)cc1C(C)(C)C</smiles>

M2, M10<smiles>CC(C)=CCc1c(O)cc(O)c2c(=O)c(O)c(-c3ccc(O)cc3)oc12</smiles>

M25<smiles>CC(C)CCc1c(O)cc(O)c2c(=O)c(O)c(-c3ccc(O)cc3)oc12</smiles>

M3, M6<smiles>C=C(C)C=Cc1c(O)cc(O)c2c(=O)c(O)c(-c3ccc(OC)cc3)oc12</smiles>

M4, M5, M7, M9, M11<smiles>COCC(C)CCc1c(O)cc(O)c2c(=O)c(O)c(-c3ccc(OC)cc3)oc12</smiles><smiles>C#CCCCC</smiles>

M15, M23<smiles>COc1ccc(-c2oc3c(CCC(C)C)c(O)cc(O)c3c(=O)c2O)cc1</smiles>

M13, M18, M26<smiles>COc1ccc(-c2oc3c(CC=C(C)C)c(O)cc(O)c3c(=O)c2O)cc1</smiles>

M1, M8<smiles>COc1ccc(-c2oc3c(CC=C(C)C)c(O)cc(O)c3c(=O)c2O)cc1</smiles><smiles>C=C(C)C=Cc1c(O)cc(O)c2c1OC(c1ccc(C)cc1)C(O)C2=O</smiles>

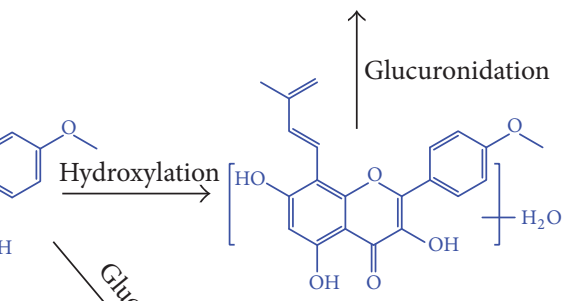

M27, M28, M29

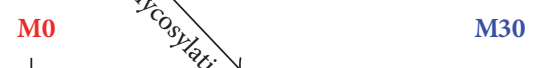<smiles>COc1ccc(COCC(CO)CCC(C)C)cc1</smiles>

M30



M12, M22, M24<smiles>COc1ccc(-c2oc3c(CC=C(C)C)c(O)cc(O)c3c(=O)c2OC)cc1</smiles>

M20

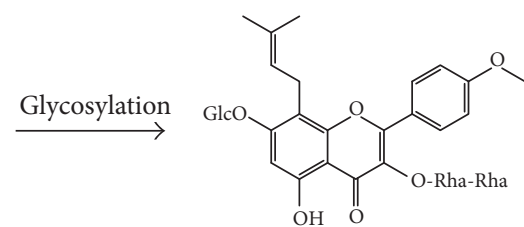

M14, M16

gluA, glucuronide conjugates; Glc, glucose; Rha, rhamnose; Xyl, xylose Red: parent drug; blue: phase I metabolites

(a)
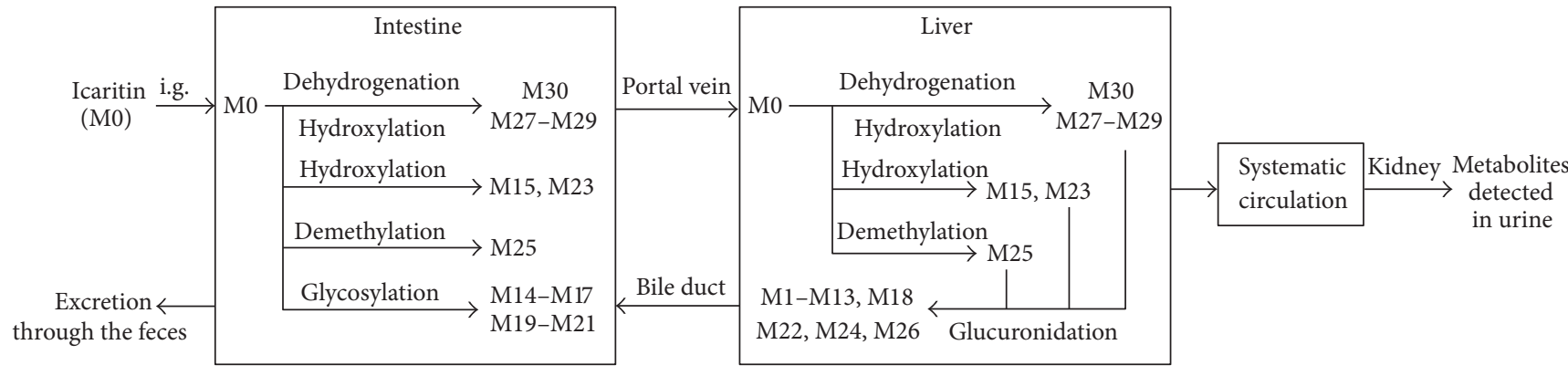

(b)

FIGURE 4: The proposed metabolic pathway (a) and metabolic sites (b) of icaritin in rats.

study could provide an experimental basis to understand the metabolic fate of icaritin in rat.

\section{Conflicts of Interest}

The authors have declared no conflicts of interest.

\section{Authors' Contributions}

Beibei Zhang, Shuzhang Du, and Xiaojian Zhang conceived and designed the experiments. Beibei Zhang and Xiaoli Chen performed the experiments. Beibei Zhang and Rui Zhang contributed analytic tools. Beibei Zhang and Fangfang Zheng 
performed data analysis. Beibei Zhang and Shuzhang Du wrote the paper.

\section{References}

[1] Editorial Committee of Pharmacopoeia of Ministry of Health PR China, The Pharmacopeoia of People's Republic of China (Part 1), Chemical Industry Press, Beijing, China, 2015.

[2] H. Ma, X. He, Y. Yang, M. Li, D. Hao, and Z. Jia, "The genus Epimedium: an ethnopharmacological and phytochemical review," Journal of Ethnopharmacology, vol. 134, no. 3, pp. 519-541, 2011.

[3] F. Xu, Y. Ding, Y. Guo et al., "Anti-osteoporosis effect of Epimedium via an estrogen-like mechanism based on a systemlevel approach," Journal of Ethnopharmacology, vol. 177, pp. 148$160,2016$.

[4] J. Zhou, J. Wu, X. Chen et al., "Icariin and its derivative, ICT, exert anti-inflammatory, anti-tumor effects, and modulate myeloid derived suppressive cells (MDSCs) functions," International Immunopharmacology, vol. 11, no. 7, pp. 890-898, 2011.

[5] S.-H. Chen, M. Lei, X.-H. Xie et al., "PLGA/TCP composite scaffold incorporating bioactive phytomolecule icaritin for enhancement of bone defect repair in rabbits," Acta Biomaterialia, vol. 9, no. 5, pp. 6711-6722, 2013.

[6] X. Lai, Y. Ye, C. Sun et al., "Icaritin exhibits anti-inflammatory effects in the mouse peritoneal macrophages and peritonitis model," International Immunopharmacology, vol. 16, no. 1, pp. 41-49, 2013.

[7] S. Peng, G. Zhang, B.-T. Zhang et al., "The beneficial effect of Icaritin on osteoporotic bone is dependent on the treatment initiation timing in adult ovariectomized rats," Bone, vol. 55, no. 1, pp. 230-240, 2013.

[8] S. W. Lei, G. Cui, G. P. H. Leung et al., "Icaritin protects against oxidative stress-induced injury in cardiac H9c2 cells via Akt/Nrf2/HO-1 and calcium signalling pathways," Journal of Functional Foods, vol. 18, pp. 213-223, 2015.

[9] J. Li, P. Liu, R. Zhang et al., "Icaritin induces cell death in activated hepatic stellate cells through mitochondrial activated apoptosis and ameliorates the development of liver fibrosis in rats," Journal of Ethnopharmacology, vol. 137, no. 1, pp. 714-723, 2011.

[10] F. Sun, I. R. Indran, Z. W. Zhang et al., "A novel prostate cancer therapeutic strategy using icaritin-activated arylhydrocarbonreceptor to co-target androgen receptor and its splice variants," Carcinogenesis, vol. 36, no. 7, pp. 757-768, 2015.

[11] M.-C. Jiang, X.-H. Chen, X. Zhao, X.-J. Zhang, and W.-F. Chen, "Involvement of IGF-1 receptor signaling pathway in the neuroprotective effects of Icaritin against MPP+-induced toxicity in MES23.5 cells," European Journal of Pharmacology, vol. 786, pp. 53-59, 2016.

[12] J. Liao, Y. Liu, H. Wu et al., "The role of icaritin in regulating Foxp3/IL17a balance in systemic lupus erythematosus and its effects on the treatment of MRL/lpr mice," Clinical Immunology, vol. 162, pp. 74-83, 2016.

[13] Y. Chen, Y. H. Zhao, X. B. Jia, and M. Hu, "Intestinal absorption mechanisms of prenylated flavonoids present in the heat-processed Epimedium koreanum Nakai (Yin Yanghuo)," Pharmaceutical Research, vol. 25, no. 9, pp. 2190-2199, 2008.

[14] J. Zhou, Y. H. Ma, Z. Zhou, Y. Chen, Y. Wang, and X. Gao, "Special section on drug metabolism and the microbiome intestinal absorption and metabolism of epimedium flavonoids in osteoporosis rats," Drug Metabolism and Disposition, vol. 43, no. 10, pp. 1590-1600, 2015.

[15] Y.-T. Wu, C.-W. Lin, L.-C. Lin, A. W. Chiu, K.-K. Chen, and T.H. Tsai, "Analysis of biliary excretion of icariin in rats," Journal of Agricultural and Food Chemistry, vol. 58, no. 18, pp. 9905-9911, 2010.

[16] H. Zhao, M. Fan, L. Fan, J. Sun, and D. Guo, "Liquid chromatography-tandem mass spectrometry analysis of metabolites in rats after administration of prenylflavonoids from Epimediums," Journal of Chromatography B: Analytical Technologies in the Biomedical and Life Sciences, vol. 878, no. 1516, pp. 1113-1124, 2010.

[17] Q. Chang, G.-N. Wang, Y. Li, L. Zhang, C. You, and Y. Zheng, "Oral absorption and excretion of icaritin, an aglycone and also active metabolite of prenylflavonoids from the Chinese medicine Herba Epimedii in rats," Phytomedicine, vol. 19, no. 11, pp. 1024-1028, 2012.

[18] Q. Qian, S.-L. Li, E. Sun et al., "Metabolite profiles of icariin in rat plasma by ultra-fast liquid chromatography coupled to triple-quadrupole/time-of-flight mass spectrometry," Journal of Pharmaceutical and Biomedical Analysis, vol. 66, pp. 392-398, 2012.

[19] Y. Jin, C.-S. Wu, J.-L. Zhang, and Y.-F. Li, "A new strategy for the discovery of epimedium metabolites using high-performance liquid chromatography with high resolution mass spectrometry," Analytica Chimica Acta, vol. 768, no. 1, pp. 111-117, 2013.

[20] L. Cui, F. Xu, J. Jiang et al., "Identification of metabolites of epimedin A in rats using UPLC/Q-TOF-MS," Chromatographia, vol. 77, no. 17-18, pp. 1223-1234, 2014.

[21] H. Liu, H. Sun, D. Lu et al., "Identification of glucuronidation and biliary excretion as the main mechanisms for gossypol clearance: in vivo and in vitro evidence," Xenobiotica, vol. 44, no. 8, pp. 696-707, 2014.

[22] F. Li, Y. Tan, H. Chen et al., "Identification of schisandrin as a vascular endothelium protective component in YiQiFuMai powder injection using HUVECs binding and HPLC-DAD-QTOF-MS/MS analysis," Journal of Pharmacological Sciences, vol. 129, no. 1, pp. 1-8, 2015.

[23] D. Lu, Z. Ma, T. Zhang, X. Zhang, and B. Wu, "Metabolism of the anthelmintic drug niclosamide by cytochrome P450 enzymes and UDP-glucuronosyltransferases: metabolite elucidation and main contributions from CYP1A2 and UGT1A1," Xenobiotica, vol. 46, no. 1, pp. 1-13, 2016.

[24] J. M. Hutzler and T. S. Tracy, "Atypical kinetic profiles in drug metabolism reactions," Drug Metabolism and Disposition, vol. 30, no. 4, pp. 355-362, 2002.

[25] US FDA, Guidance for Industry: Bioanalytical Method Validation, US Department of Health and Human Services, Center for Drug Evaluation and Research (CDER), http://www.fda.gov/ cder/guidance, 2001.

[26] B. K. Matuszewski, M. L. Constanzer, and C. M. Chavez-Eng, "Matrix effect in quantitative LCMSMS analyses of biological fluids: a method for determination of finasteride in human plasma at picogram per milliliter concentrations," Analytical Chemistry, vol. 70, no. 5, pp. 882-889, 1998.

[27] J. Troberg, E. Järvinen, G. Ge, L. Yang, and M. Finel, "UGT1A10 Is a high activity and important extrahepatic enzyme: why has its role in intestinal glucuronidation been frequently underestimated?" Molecular Pharmaceutics, Ahead of Print, 2016.

[28] D. Lu, H. Liu, W. Ye, Y. Wang, and B. Wu, "Structure- and isoform-specific glucuronidation of six curcumin analogs," Xenobiotica, pp. 1-10, 2016. 
[29] H. Sun, H. Wang, H. Liu, X. Zhang, and B. Wu, "Glucuronidation of capsaicin by liver microsomes and expressed UGT enzymes: reaction kinetics, contribution of individual enzymes and marked species differences," Expert Opinion on Drug Metabolism and Toxicology, vol. 10, no. 10, pp. 1325-1336, 2014.

[30] X. Wang, "Studies on serum pharmacochemistry of traditional Chiese medicine," World Science And Technology/Modernization of Traditional Chinese Medicine, vol. 4, no. 2, pp. 1-4, 2002.

[31] R. Zhang, S. Gilbert, X. Yao et al., "Natural compound methyl protodioscin protects against intestinal inflammation through modulation of intestinal immune responses," Pharmacology Research Perspectives, vol. 3, article e00118, no. 2, 2015.

[32] B. Wu, K. Kulkarni, S. Basu, S. Zhang, and M. Hu, "First-pass metabolism via UDP-glucuronosyltransferase: a barrier to oral bioavailability of phenolics," Journal of Pharmaceutical Sciences, vol. 100, no. 9, pp. 3655-3681, 2011.

[33] B. Wu, D. Dong, M. Hu, and S. Zhang, "Quantitative prediction of glucuronidation in humans using the in vitro-in vivo extrapolation approach," Current Topics in Medicinal Chemistry, vol. 13, no. 11, pp. 1343-1352, 2013. 

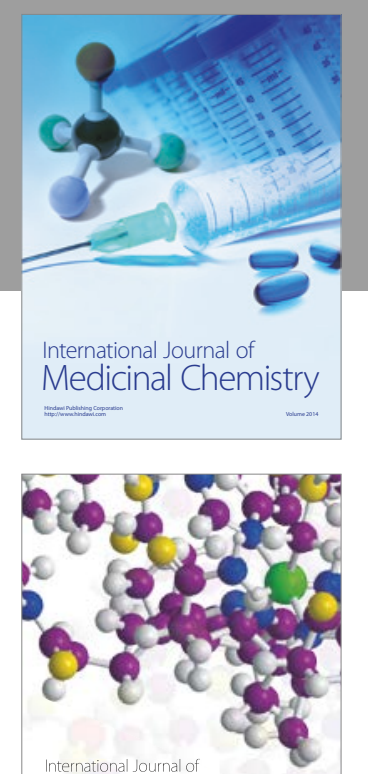

Carbohydrate Chemistry

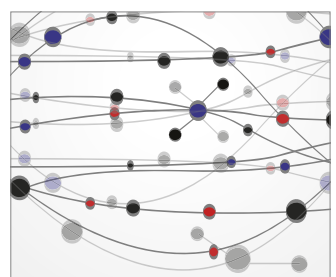

The Scientific World Journal
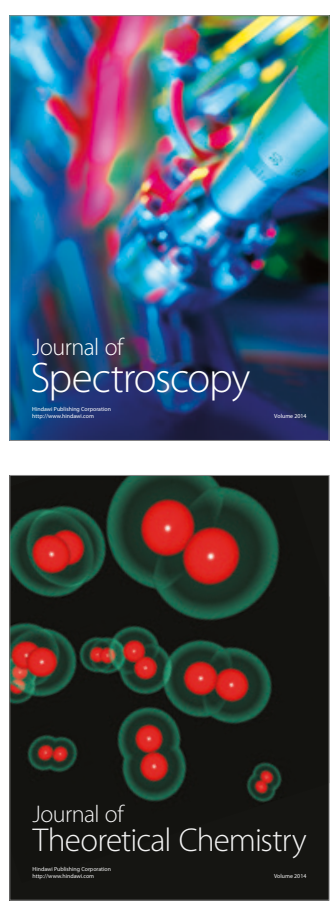
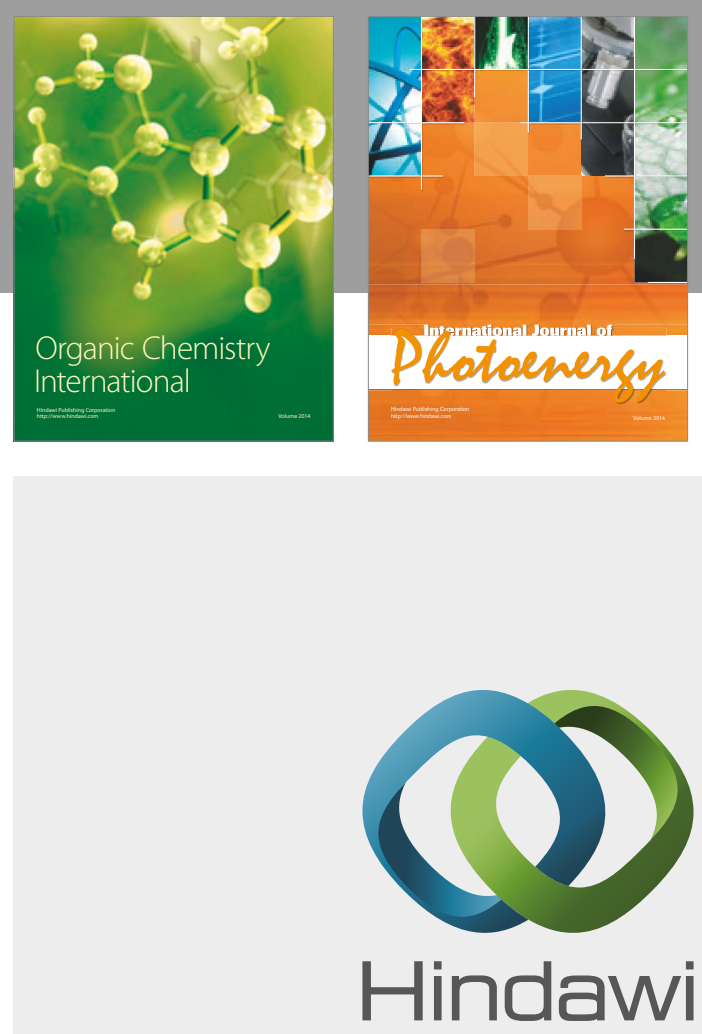

Submit your manuscripts at

https://www.hindawi.com

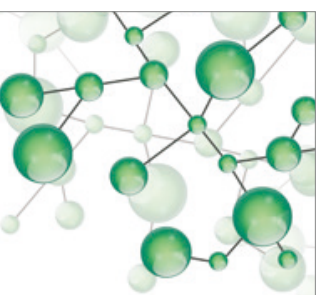

International Journal of

Inorganic Chemistry



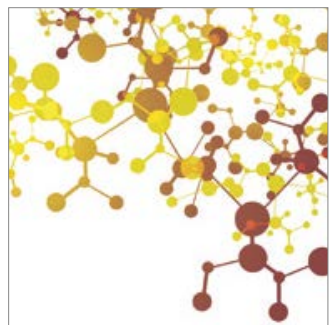

Applied Chemistry
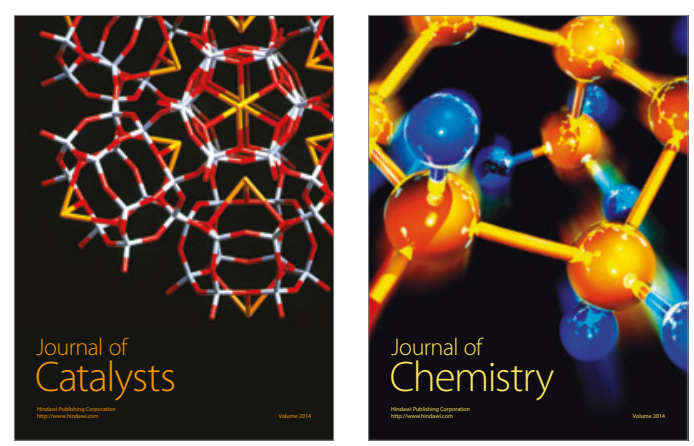
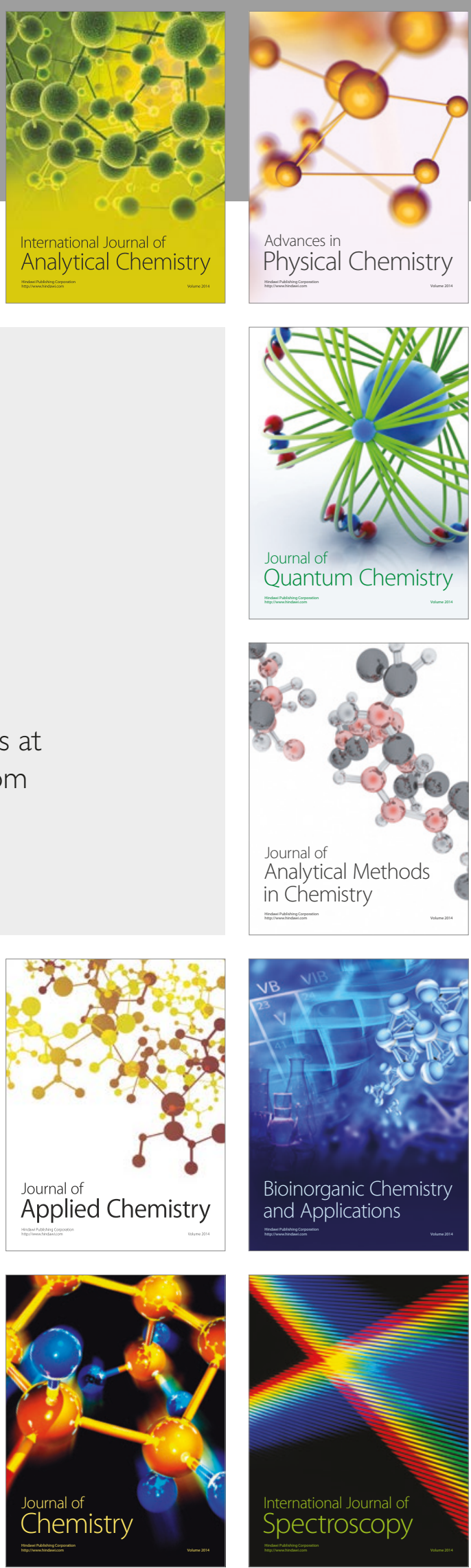